\title{
IMPLEMENTASI ALGORITMA APRIORI TERHADAP DATA PENJUALAN PADA PERUSAHAAN RETAIL
}

\author{
Jordy Lasmana Putra1; Mugi Raharjo²; Tommi Alfian Armawan Sandi ${ }^{3}$ Ridwan ${ }^{4}$; Rizal Prasetyo5; \\ 1Program Studi Magister Ilmu Komputer \\ STMIK Nusa Mandiri Jakarta \\ www.nusamandiri.ac.id \\ balakusalo@gmail.com ; mugimou@gmail.com ; alfian.armawan@gmail.com ; ridwans70@gmail.com ; \\ prasetyorizal3@gmail.com
}

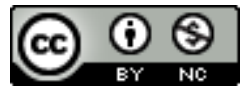

Ciptaan disebarluaskan di bawah Lisensi Creative Commons Atribusi-NonKomersial 4.0 Internasional.

\begin{abstract}
The development of the business world is increasingly rapid, so it needs a special strategy to increase the turnover of the company, in this case the retail company. In increasing the company's turnover can be done using the Data Mining process, one of which is using a priori algorithm. With a priori algorithm can be found association rules which can later be used as patterns of purchasing goods by consumers, this study uses a repository of 209 records consisting of 23 transactions and 164 attributes. From the results of this study, the goods with the name CREAM CUPID HEART COAT HANGER are the products most often purchased by consumers. By knowing the pattern of purchasing goods by consumers, the company management can increase the company's turnover by referring to the results of processing sales transaction data using a priori algorithm.
\end{abstract}

Keywords: Apriori Algorithm, Transcation Data, retail

Intisari - Perkembangan dunia bisnis saat ini semakin pesat, sehingga perlu strategy khusus untuk meningkatkan omset perusahaan, dalam kasus ini adalah peruashaan retail. Dalam meningkatkan omset perusahaan dapat dilakukan dengan menggunakan proses Data Mining, salah satunya adalah dengan menggunakan algoritma apriori. Dengan algoritma apriori dapat ditemukan aturan asosiasi yang nantinya dapat dijadikan sebagai pola pembelian barang oleh konsumen, penelitian ini menggunakan data repository sebanyak 209 record yang terdiri dari 23 transaksi dan 164 attribute. Dari hasil penelitian ini didapatkan barang dengan nama CREAM CUPID HEART COAT HANGER adalah produk yang paling sering dibeli oleh para konsumen. Dengan diketahuinya pola pembelian barang oleh konsumen, pihak pengelola perusahaan dapat meningkatkan omset perusahaan dengan mengacu kepada hasil dari pengolahan data transaksi penjualan dengan menggunakan algoritma apriori.

Kata Kunci: Algoritma Apriori, Data Penjualan, retail

\section{PENDAHULUAN}

Dunia bisnis sekarang ini banyak perusahaan bersaing untuk meningkatkan omset perusahaan. Persaingan ini disebabkan karena banyaknya perusahaan yang bergerak di bidang yang sama, seperti halnya yang terjadi pada perusahaan yang bergerak dibidang retail.

Perusahaan retail berkembang begitu pesat sehingga memungkinkan adanya permasalahan yang sering dihadapi oleh perusahaan, antara lain belum adanya sistem yang mengatasi mengenai tata letak produk. Sistem tata letak produk ini dilakukan untuk memberikan kemudahan kepada para konsumen saat melakukan proses berbelanja (Arifianti, 2016).

Selain dari pada permasalahan tata letak produk, permasalahan lain yaitu belum adanya sistem untuk mengefisiensikan stock barang. Selama ini kebanyakan perusahaan melakukan pemesanan barang kepada pihak ketiga hanya dengan mengira-ngira ketika jumlah barang di gudang hampir habis (Fauziah \& Ratnawati, 2018). Selain itu masih ada beberapa perusahaan yang belum mengetahui pola pembelian barang konsumen, yang dimana pola pembelian barang ini meliputi barang apa saja yang biasa konsumen beli secara bersamaan dalam satu transaksi pembelian, misalkan konsumen 1 membeli produk A, konsumen juga membeli produk B, C, dan seterusnnya. Hal ini menjadi masalah karena kebanyakan data transaksi penjualan hanya dijadikan arsip saja tanpa dimanfaatkan dengan baik (Santoso, Hariyadi, \& Prayitno, 2016). 
Padahal dari kumpulan data tersebut memiliki banyak informasi yang sangat bermanfaat untuk dapat dimanfaatkan, salah satunya untuk mengetahui pola pembelian barang konsumen.

Berdasarkan latar belakang diatas penulis merumuskan masalah yang akan dibahas di dalam penelitian ini, antara lain sebagai berikut :

1. Bagaimana menerapkan algoritma apriori untuk menentukan pola pembelian barang konsumen?

2. Bagaimana menerapkan algoritma apriori untuk mengetahui barang apa saja yang sering dibeli?

Data mining merupakan proses analisa data untuk menemukan suatu pola dari kumpulan data Tersebut (Gunadi \& Sensuse, 2016). Data mining mampu menganalisa dan mengolah sekumpulan data menjadi sebuah informasi yang dapat menentukan pola-pola yang dapat menunjang sebuah keputusan.

Ada beberapa algoritma pada data mining yang dapat kita gunakan untuk memprediksikan suatu hasil dari pengolahan sekumpulan data. Salah satunya adalah dengan menggunakan algoritma apriori.

Analisis Apriori didefenisikan suatu proses untuk menemukan semua aturan apriori yang memenuhi syarat minimum untuk support dan syarat minimum untuk (Gunadi \& Sensuse, 2016). Algoritma apriori biasa digunakan dalam mencari sebuah pola pembelian suatu barang dari sekumpulan data.

Ditambah dengan metode market basket analysis, kita dapat mengetahui dan memprediksi pola pembelian konsumen, ketika konsumen membeli barang A, dimungkinkan untuk membeli barang $B$ dengan dilihat dari prosentase kedekatan antara barang A dan barang B. Data yang digunakan dalam penelitian ini merupakan data repository yang bersumber dari https://www.kaggle.com.

Dengan adanya penelitian ini diharapkaan dapat meningkatkan omset perusahaan, karena dengan mengetahui pola pembelian barang konsumen, perusahaan dapat menentukan penempatan tata letak produk-produk yang di jual, sehingga dengan peletakan produk yang disesuaikan dengan pola pembelian barag konsumen, konsumen dapat membeli produk lain selain produk utama yang dibelinya, perusahaan juga dapat mengefisienkan pembelian stock barang berikutnya, dan meminimalisir penumpukan stock barang tertentu karena sudah diketahui barang apa saja yang paling sering dibeli dan jarang dibeli oleh konsumen, khususnya diimplementasikan pada perusahaan retail.

\section{BAHAN DAN METODE \\ Data Mining (CRISP-DM)}

Berikut ini adalah penjelasan mengenai enam tahap Siklus hidup proyek data mining menurut Cross-Industry Standart Proses for Data Mining(CRISP-DM)yang dikembangkan tahun 1996 terbagi dalam 6 fase (Kusrini \& Luthfi, 2009).

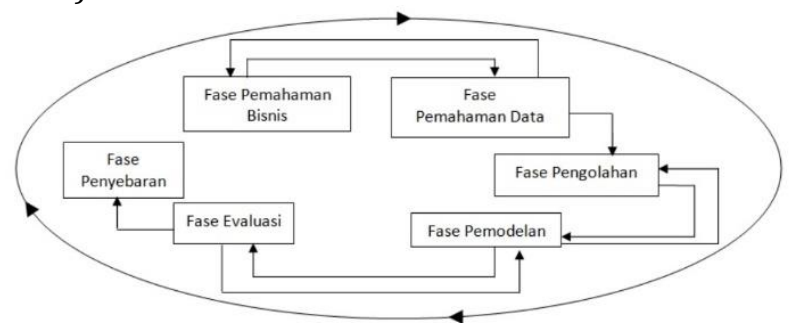

Sumber : (Nursanti \& Vydia, 2013)

Gambar 1. Proses Data Mining menurut CRISP-DM

Berikut ini merupakan penjelasan dari gambar di atas :

1. Fase Pemahaman Bisnis (Business Understanding Phase)

a. Penentuan tujuan proyek dan kebutuhan secara detail dalam lingkup bisnis atau unit penelitian secara keseluruhan.

b. Menerjemahkan tujuan dan batasan menjadi formula dari permasalahan data mining.

c. Menyiapkan strategi awal untuk mencapai tujuan.

2. Fase pemahaman data (Data Understanding Phase)

a. Mengumpulkan data.

b. Menggunakan analisis penyelidikan data untuk mengenali lebih lanjut data dan pencarian pengetahuan awal.

c. Mengevaluasi kualitas data.

d. Jika diinginkan, pilih sebagian kecil group data yang mungkin mengundang pola dari permasalahan.

3. Fase pengolahan data (Data Preparation Phase)

a. Siapkan data awal, kumpulkan data yang akan digunakan untuk keseluruhan fase berikutnya. Fase ini merupakan pekerjaan berat yang perlu dilaksanakan secara intensif.

b. Pilih kasus dan variabel yang ingin dianalisis dan yang sesuai analisis yang akan dilakukan.

c. Lakukan perubahan pada beberapa variabel jika dibutuhkan.

d. Siapkan data awal sehingga siap untuk perangkat pemodelan.

4. Fase Pemodelan (Modelling Phase) 
a. Pilih dan aplikasikan teknik pemodelan yang sesuai.

b. Perlu diperhatikan bahwa beberapa teknik mungkin untuk digunakan pada permasalahan data mining yang sama.

c. Jika diperlukan, proses dapat kembali ke fase pengolahan data untuk menjadikan data ke dalam bentuk yang sesuai dengan spesifikasi kebutuhan teknik data mining tertentu.

5. Fase Evaluasi

a. Pengevaluasi satu atau lebih model yang digunakan dalam fase permodelan untuk mendapatkan kualitas dan efektivitas sebelum disebarkan untuk digunakan.

b. Menetapkan apakah terdapat model yang memenihi tujuan pada fase awal.

c. Menentukan apakah terdapat permasalahan penting dari bisnis atau penelitian yang tidak tertangani degan baik.

d. Mengambil keputusan yang berkaitan dengan penggunaan hasil dari data mining.

6. Fase Penyebaran

a. Menggunakan model yang dihasilkan. Terbentuknya model tidak menandakan telah terselesaikannya proyek.

b. Contoh sederhana penyebaran: pembuatan laporan.

c. Contoh kompleks penyebaran: penerapan proses data mining secara paralel pada department lain.

\section{Association Rule atau Aturan Asosiasi}

Merupakan ikatan atau bias juga di sebut hubungan "apa dengan apa”. Aturan asosiasi juga sering dinamakan market basket analysis (analisis keranjang

belanja), atau bisa dinamakan aturan asosiasi dalam bentuk "if-then" atau "jika-maka". Aturan ini dihitung dari sekumpulan data yang sifatnya probabilitas (Robi Yanto, 2015). Contoh asosiasi dalam sebuah penelitian, yaitu dengan menemukan barang dalam perusahaan retail yang sering dibeli secara bersamaan, dan barang yang tidak pernah diberi secara bersamaan. Interestingness measure yang digunakan adalah:

a. Support, adalah suatu ukuran yang menunjukkan seberapa besar tingkat dominasi suatu item atau itemset dari keseluruhan transaksi.

b.Confidence, adalah suatu ukuran yang menunjukkan hubungan antar dua item secara conditional (berdasarkan suatu kondisi tertentu).
Pencarian pola kaidah asosiasi mengunakan dua buah parameter nilai yaitu dukungan (support) dan keterpercayaan (confidence) yang memiliki rentang nilai antara $0 \%-100 \%$ (GIBRAN, 2016).

Metodologi dasar analisis asosiasi terbagi menjadi dua tahap:

1. Analisa pola frekuensi tinggi Tahap ini mencari kombinasi item yang memenuhi syarat minimum dari nilai support dalam database. Nilai support sebuah item diperoleh dengan rumus berikut:

$\operatorname{Support}(A)$

$$
=\frac{\Sigma \text { TransaksiMengandungA }}{\text { Total Transaksi }} * 100 \%
$$

2. Pembentukan aturan assosiatif Setelah semua pola frekuensi tinggi ditemukan, barulah dicari aturan assosiatif yang memenuhi syarat minimum untuk confidence dengan menghitung confidence aturan assosiatif A _B Nilai confidence dari aturan A_B diperoleh dari rumus berikut: Confidence $(A \rightarrow B)$

$=\frac{\Sigma \text { TransaksiMengandungA \& BgA }}{\Sigma \text { TransaksiMengandung } A} * 100 \% \ldots \ldots$

\section{Algoritma Apriori}

Algoritma yang berpengaruh untuk mining frequent Itemset untuk aturan asosiasi (Gunadi \& Sensuse, 2016) Algoritma apriori termasuk jenis aturan asosiasi pada data mining. Aturan yang menyatakan asosiasi antara beberapa atribut sering disebut affinity analysis atau market basket analysis. Analisis asosiasi atau association rule mining adalah teknik data mining untuk menemukan aturan suatu kombinasi item. Salah satu tahap analisis asosiasi yang menarik perhatian banyak peneliti untuk menghasilkan algoritma yang efisien adalah analisis pola frekuensi tinggi (frequent pattern mining). Penting tidaknya suatu asosiasi dapat diketahui dengan dua tolak ukur, yaitu: support dan confidence. Support (nilai penunjang) adalah persentase kombinasi item tersebut dalam database, sedangkan confidence (nilai kepastian) adalah kuatnya hubungan antar-item dalam aturan asosiasi.

\section{HASIL DAN PEMBAHASAN}

Algoritma apriori biasa digunakan untuk mencari aturan asosiasi yang dapat memenuhi syarat minimum support (nilai penunjang), yang dimana merupakan kombinasi tiap item dalam 
database. Dan syarat minimum confidence (nilai kepastian), yang dimana merupakan kuatnya hubungan antar item dalam aturan asosiasi.

\section{Pembentukan 1 Itemset}

Berikut adalah proses penyelesaian dari pembentukan 1 item set dengan jumlah minimum support $10 \%$ dengan rumus:

$$
=\frac{\text { Spemilihan mengandung } A}{\Sigma \text { pemilihan }} * 100 \%
$$

Tabel 1. Item Set

\begin{tabular}{clc}
\hline No & \multicolumn{1}{c}{ Item Set } & Support \\
\hline 1 & $\begin{array}{l}\text { GLASS STAR FROSTED T-LIGHT } \\
\text { HOLDER }\end{array}$ & $13 \%$ \\
\hline 2 & $\begin{array}{l}\text { CREAM CUPID HEARTS COAT } \\
\text { HANGER }\end{array}$ & $13 \%$ \\
\hline 3 & $\begin{array}{l}\text { KNITTED UNION FLAG HOT } \\
\text { WATER BOTTLE }\end{array}$ & $13 \%$ \\
\hline 4 & $\begin{array}{l}\text { CREAM CUPID HEARTS COAT } \\
\text { HANGER }\end{array}$ & $13 \%$ \\
\hline 5 & $\begin{array}{l}\text { RED WOOLLY HOTTIE WHITE } \\
\text { HEART. }\end{array}$ & $13 \%$ \\
\hline 6 & $\begin{array}{l}\text { CREAM CUPID HEARTS COAT } \\
\text { HANGER }\end{array}$ & $13 \%$ \\
\hline 7 & $\begin{array}{l}\text { SET 7 BABUSHKA NESTING } \\
\text { BOXES }\end{array}$ & $13 \%$ \\
\hline 8 & $\begin{array}{l}\text { CREAM CUPID HEARTS COAT } \\
\text { HANGER }\end{array}$ & $13 \%$ \\
\hline 9 & $\begin{array}{l}\text { WHITE HANGING HEART T- } \\
\text { LIGHT HOLDER }\end{array}$ & $13 \%$ \\
\hline 10 & $\begin{array}{l}\text { CREAM CUPID HEARTS COAT } \\
\text { HANGER }\end{array}$ & $13 \%$ \\
\hline Sumber: Putra (2019) & \\
\hline
\end{tabular}

Sumber: Putra (2019)

\section{Pembentukkan 2 Item set}

Berikut adalah proses penyelesaian dari pembentukan 2 item set dengan jumlah minimum support $10 \%$ dengan rumus:

$$
=\frac{\text { Epemilihan mengandung } A \cap B}{\text { pemilihan }} * 100 \%
$$

Tabel 2. Item Set

\begin{tabular}{|c|c|c|}
\hline No & Item Set & Support \\
\hline & FLAG HOT WATER BOTTLE & \\
\hline \multirow{3}{*}{5} & RED WOOLLY HOTTIE WHITE & \multirow{3}{*}{$13 \%$} \\
\hline & HEART. CREAM CUPID HEARTS & \\
\hline & COAT HANGER & \\
\hline \multirow{3}{*}{6} & CREAM CUPID HEARTS COAT & \multirow{3}{*}{$13 \%$} \\
\hline & HANGER, RED WOOLLY & \\
\hline & HOTTIE WHITE HEART. & \\
\hline \multirow{3}{*}{7} & SET 7 BABUSHKA NESTING & \multirow{3}{*}{$13 \%$} \\
\hline & BOXES, CREAM CUPID HEARTS & \\
\hline & COAT HANGER & \\
\hline \multirow{3}{*}{8} & CREAM CUPID HEARTS COAT & \multirow{3}{*}{$13 \%$} \\
\hline & HANGER, SET 7 BABUSHKA & \\
\hline & NESTING BOXES & \\
\hline \multirow{3}{*}{9} & WHITE HANGING HEART T- & \multirow{3}{*}{$13 \%$} \\
\hline & LIGHT HOLDER, CREAM CUPID & \\
\hline & HEARTS COAT HANGER & \\
\hline \multirow{3}{*}{10} & CREAM CUPID HEARTS COAT & \multirow{3}{*}{$13 \%$} \\
\hline & HANGER, WHITE HANGING & \\
\hline & HEART T-LIGHT HOLDER & \\
\hline
\end{tabular}

\begin{tabular}{clc}
\hline No & \multicolumn{1}{c}{ Item Set } & Support \\
\hline \multirow{3}{*}{1} & $\begin{array}{l}\text { GLASS STAR FROSTED T-LIGHT } \\
\text { HOLDER, CREAM CUPID } \\
\text { HEARTS COAT HANGER }\end{array}$ & $13 \%$ \\
\hline \multirow{3}{*}{2} & $\begin{array}{l}\text { CREAM CUPID HEARTS COAT } \\
\text { HANGER, GLASS STAR }\end{array}$ & $13 \%$ \\
& FROSTED T-LIGHT HOLDER & \\
\hline \multirow{3}{*}{3} & $\begin{array}{l}\text { KNITTED UNION FLAG HOT } \\
\text { WATER BOTTLE, CREAM CUPID }\end{array}$ & $13 \%$ \\
& HEARTS COAT HANGER & \\
\hline \multirow{2}{*}{4} & $\begin{array}{l}\text { CREAM CUPID HEARTS COAT } \\
\text { HANGER, KNITTED UNION }\end{array}$ & $13 \%$ \\
\hline
\end{tabular}

Sumber : (Putra, 2019)

\section{Pembentukan Aturan Asosiasi}

Setelah terbentuk item set, selanjutnya dicari aturan asosiasi yang memenuhi syarat minimum untuk confidence dengan menghitung confidence aturan asosiasi A ke $\mathrm{B}$, dengan minimal confidence $=90 \%$.

Untuk menemukan nilai confidence dari aturan A ke $\mathrm{B}$ dengan rumus :

$=\frac{\Sigma \text { pemilihan mengandung } A \cap B}{\text { spemilihan mengandung } \mathrm{A}} * 100 \% \ldots \ldots$

Dengan rumus diatas dapat diperoleh nilai confidence dari 2 item set seperti table di bawah ini:

Tabel 3. Aturan Asosiasi

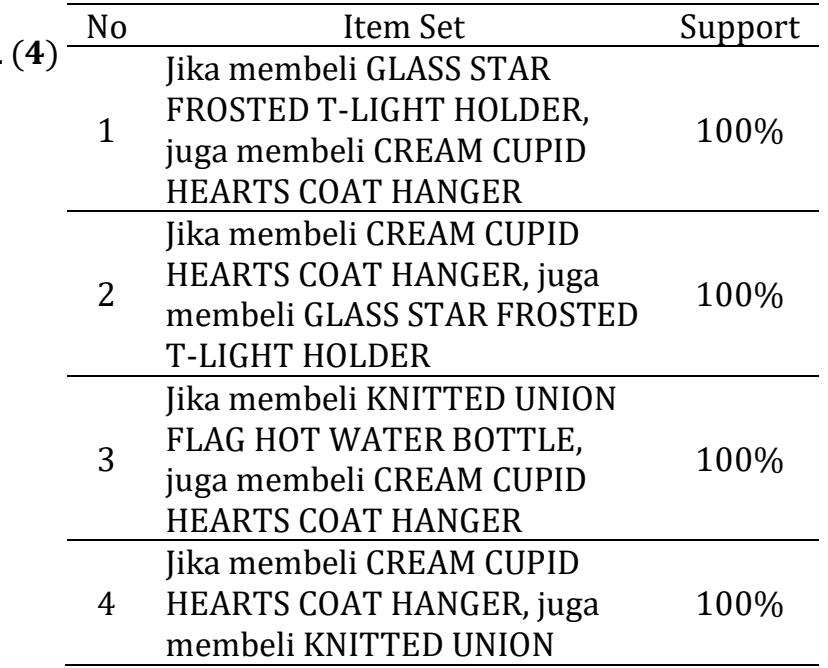




\begin{tabular}{|c|c|c|}
\hline No & Item Set & Support \\
\hline & FLAG HOT WATER BOTTLE & \\
\hline 5 & $\begin{array}{l}\text { Jika membeli RED WOOLLY } \\
\text { HOTTIE WHITE HEART. juga } \\
\text { membeli CREAM CUPID } \\
\text { HEARTS COAT HANGER }\end{array}$ & $100 \%$ \\
\hline 6 & $\begin{array}{l}\text { Jika membeli CREAM CUPID } \\
\text { HEARTS COAT HANGER, juga } \\
\text { membeli RED WOOLLY HOTTIE } \\
\text { WHITE HEART. }\end{array}$ & $100 \%$ \\
\hline 7 & $\begin{array}{l}\text { Jika membeli SET } 7 \text { BABUSHKA } \\
\text { NESTING BOXES, juga membeli } \\
\text { CREAM CUPID HEARTS COAT } \\
\text { HANGER }\end{array}$ & $100 \%$ \\
\hline 8 & $\begin{array}{l}\text { Jika membeli CREAM CUPID } \\
\text { HEARTS COAT HANGER, juga } \\
\text { membeli SET } 7 \text { BABUSHKA } \\
\text { NESTING BOXES }\end{array}$ & $100 \%$ \\
\hline 9 & $\begin{array}{l}\text { Jika membeli WHITE HANGING } \\
\text { HEART T-LIGHT HOLDER, juga } \\
\text { membeli CREAM CUPID } \\
\text { HEARTS COAT HANGER }\end{array}$ & $100 \%$ \\
\hline 10 & $\begin{array}{l}\text { Jika membeli CREAM CUPID } \\
\text { HEARTS COAT HANGER, juga } \\
\text { membeli WHITE HANGING } \\
\text { HEART T-LIGHT HOLDER }\end{array}$ & $100 \%$ \\
\hline
\end{tabular}

Sumber : (Putra, 2019)

Data diatas merupakan hasil perhitungan manual menggunakan rumus di excel, nah apabila menggunakan tools, dalam kasus ini penulis menggunakan Rapid Miner Studio 9.1 yang dimana hasil yang ditampilkan merupakan hasil terbaik dari aturan yang ada. Berikut adalah tampilan hasil menggunakan Rapid Miner Studio 9.1:

1. Quantity_GLASS STAR FROSTED T-LIGHT HOLDER=true $3==>$ Quantity_CREAM CUPID HEARTS COAT HANGER=true 3

2. Quantity_CREAM CUPID HEARTS COAT HANGER=true $3==>$ Quantity_GLASS STAR FROSTED T-LIGHT HOLDER=true 3

3. Quantity_KNITTED UNION FLAG HOT WATER BOTTLE=true 3 ==> Quantity_CREAM CUPID HEARTS COAT HANGER=true 3

4. Quantity_CREAM CUPID HEARTS COAT HANGER=true $3==>$ Quantity_KNITTED UNION FLAG HOT WATER BOTTLE=true 3

5. Quantity_RED WOOLLY HOTTIE WHITE HEART.=true $3==>$ Quantity_CREAM CUPID HEARTS COAT HANGER=true 3
6. Quantity_CREAM CUPID HEARTS COAT HANGER=true 3 ==> Quantity_RED WOOLLY HOTTIE WHITE HEART.=true 3

7. Quantity_SET 7 BABUSHKA NESTING BOXES=true $3==>$ Quantity_CREAM CUPID HEARTS COAT HANGER=true 3

8. Quantity_CREAM CUPID HEARTS COAT HANGER=true $3==>$ Quantity_SET 7 BABUSHKA NESTING BOXES=true 3

9. Quantity_WHITE HANGING HEART T-LIGHT HOLDER=true $3==>$ Quantity_CREAM CUPID HEARTS COAT HANGER=true 3

10. Quantity_CREAM CUPID HEARTS COAT HANGER=true $3==>$ Quantity_WHITE HANGING HEART T-LIGHT HOLDER=true 3

$$
\begin{aligned}
& \text { Berikut ini merupakan cara membaca } \\
& \text { dari hasil perhitungan diatas yang } \\
& \text { menggunakan tools Rapid Miner Studio 9.1: }
\end{aligned}
$$

1. Apabila konsumen membeli GLASS STAR FROSTED T-LIGHT HOLDER, konsumen juga akan membeli CREAM CUPID HEARTS COAT HANGER dengan nilai confidence 100\%.

2. Apabila konsumen membeli CREAM CUPID HEARTS COAT HANGER, konsumen juga akan membeli GLASS STAR FROSTED T-LIGHT HOLDER dengan nilai confidence 100\%.

3. Apabila konsumen membeli KNITTED UNION FLAG HOT WATER BOTTLE, konsumen juga akan membeli CREAM CUPID HEARTS COAT HANGER dengan nilai confidence $100 \%$.

4. Apabila konsumen membeli CREAM CUPID HEARTS COAT HANGER, konsumen juga akan membeli KNITTED UNION FLAG HOT WATER BOTTLE dengan nilai confidence 100\%.

5. Apabila konsumen membeli RED WOOLLY HOTTIE WHITE HEART, konsumen juga akan membeli CREAM CUPID HEARTS COAT HANGER dengan nilai confidence $100 \%$.

6. Apabila konsumen membeli CREAM CUPID HEARTS COAT HANGER, konsumen juga akan membeli RED WOOLLY HOTTIE WHITE HEART dengan nilai confidence $100 \%$.

7. Apabila konsumen membeli SET 7 BABUSHKA NESTING BOXES, konsumen juga akan 
membeli CREAM CUPID HEARTS COAT HANGER dengan nilai confidence 100\%.

8. Apabila konsumen membeli CREAM CUPID HEARTS COAT HANGER, konsumen juga akan membeli SET 7 BABUSHKA NESTING BOXES dengan nilai confidence $100 \%$.

9. Apabila konsumen membeli WHITE HANGING HEART T-LIGHT HOLDER, konsumen juga akan membeli CREAM CUPID HEARTS COAT HANGER dengan nilai confidence $100 \%$.

10. Apabila konsumen membeli CREAM CUPID HEARTS COAT HANGER, konsumen juga akan membeli WHITE HANGING HEART T-LIGHT HOLDER dengan nilai confidence 100\%.

\section{KESIMPULAN}

Penelitian ini menghasilkan data yang dimana data tersebut merupakan aturan asosiasi dari kumpulan data transaksi penjualan pada perusahaan retail. Dari aturan asosiasi tersebut dapat diperoleh pola pembelian barang, yang dimana para customer lebih sering membeli barang Cream Cupid Heart Coat Hanger, terbukti dari hasil perhitungan menggunakan Algoritma Apriori, bahwa item dengan nama Cream Cupid Heart Coat Hanger yang paling sering muncul dan menjadi pilihan bagi para konsumen ketika berbelanja.

Sehingga dengan diketahuinya pola pembelian barang tersebut, maka pihak pengelola perusahaan dapat memprediksi kebutuhan market yang akan datang, dan dapat memperhitungkan stock barang apa saja yang harus diperbanyak karena banyak peminatnya, dan barang apa saja yang stocknya harus dikurangi karena peminat yang kurang, dan juga dengan hasil asosiasi tersebut pihak pengelola dapat mengatur tata letak produk menjadi lebih baik karena mendekatkan produk-produk yang sering di beli bersamaan oleh para customer. Sehingga dengan diketahuinya pola pembelian barang tersebut, dapat lebih meningkatkan omset perusahaan.

Dengan pengolahan data asosiasi yang baik apabila diterapkan dengan baik pula akan sangat membantu dalam meningkatkan omset perusahaan. Untuk mengolah data asosiasi dapat pula menggunakan algoritma lain tidak hanya menggunakan algoritma apriori seperti yang penulis terapkan dalam penelitian ini, antara lain ada algoritma FGGrowth, algorritma Tertius, algoritma Generalized Sequential Patter (GSP), dan lain sebagainya untuk dapat dijadikan sebagai comparasi dalam mencari hasil yang lebih akurat.

\section{REFERENSI}

Arifianti, R. (2016). ANALISIS TATA LETAK DALAM PERSPEKTIF RITEL Ria. AdBispreneur, 1(3), 251-258.

Fauziah, S., \& Ratnawati. (2018). Penerapan Metode FIFO Pada Sistem Informasi Persediaan Barang. Jurnal Teknik Komputer, 4(1), 98-108.

GIBRAN, R. (2016). Analisis Aturan Asosiasi Menggunakan Algoritma Apriori Untuk Menentukan Inventori Apotek. Skripsi, Fakultas Ilmu Komputer, (5).

Gunadi, G., \& Sensuse, D. I. (2016). Penerapan metode data mining market basket analysis terhadap data penjualan produk buku dengan menggunakan algoritma apriori dan frequent pattern growth (fp-growth): studi kasus percetakan PT. Gramedia. Telematika MKOM, 4(1), 118-132.

Kusrini, \& Luthfi, E. T. (2009). Algoritma Data Mining - Kusrini, Emha taufiq luthfi, Universitas Amikom - Google Buku. (Theresia Ari Prabawati, Ed.). C.V ANDI OFFSET. Retrieved from https://books.google.co.id/books?id=Ojclag7308C\&printsec=frontcover\&hl=id\#v =onepage $\& \mathrm{q} \& \mathrm{f}=$ false

Nursanti, I., \& Vydia, V. (2013). Market Basket Analysis Pada Perusahaan, 11(1), 13-22.

Robi Yanto, R. K. (2015). Implementasi Data Mining dengan Metode Algoritma Apriori dalam Menentukan Pola Pembelian Obat. Implementasi Data Mining Dengan Metode Algoritma Apriori Dalam Menentukan Pola Pembelian Obat, Citec Journal, Vol. 2, No(ISSN: $\quad$ 2354-5771), 102-113. https://doi.org///dx.doi.org/10.4236/ce.20 16.71020

Santoso, H., Hariyadi, I. P., \& Prayitno. (2016). Data Mining Analisa Pola Pembelian Produk Dengan Menggunakan Metode Algoritma Apriori. Teknik Informatika. ISSN : 23023805, (1), 19-24. Retrieved from http://ojs.amikom.ac.id/index.php/semnast eknomedia/article/download/1267/1200 